\title{
Role model: Abdallah Al-Mohammad
}

\section{Adrian O'Dowd speaks to Abdallah Al-Mohammad, a consultant cardiologist and heart failure specialist at the Sheffield Teaching Hospitals NHS Foundation Trust}

\section{Adrian O’Dowd}

London

Coming from Syria to work as a doctor in the UK more than 30 years ago turned out to be the right move for Abdallah Al-Mohammad as well as for the NHS.

He qualified as a doctor in 1985 at the University of Damascus but spent some of his elective period as a medical student in Leeds and Belfast. That exposure to the UK made its mark on him.

"I did like the British system, although it was difficult for a foreign graduate. I liked the fact that you don't easily become a consultant-you have to go through difficult and long term training before you are allowed to be independent,"

Al-Mohammad says.

"When I was in Belfast in 1983, on one ward there was a wealthy man and another of no fixed abode. Both had liver failure and both were treated with the same care and respect. This was a pivotal moment in my love for the NHS."

After emigrating to the UK in 1987, Al-Mohammad completed training in general internal medicine and cardiology in hospitals in England, Scotland, and Wales before being appointed as a consultant cardiologist at Sheffield Teaching Hospitals NHS Foundation Trust in 2001. He is now lead cardiologist for heart failure services there and has a special interest in cardiac imaging.

"Two things made me want to go into medicine," he says. "The first was seeing my little sister, who had a serious illness, in the emergency department when I was 12 . I remember I liked the role of the doctors who worked with my sister. The second was watching TV in the 1970s when the first balloon coronary angioplasty was on the news. I watched that and said, 'I want to do this'."

Although Al-Mohammad initially found it difficult to get started in the UK, he soon secured a job working at Birmingham City Hospital and has since worked in all four UK countries.

He gained his British citizenship in the late 1990s, although that was not his original plan. "When I left Damascus, I said to my parents I was coming back in 15 years, because I reckoned that period was necessary for me to become a consultant.

"However, several events resulted in my decision to stay in the UK. I wasn't expecting what is happening in Syria now. It was beyond my wildest possible nightmares. I took the final decision to stay here in 2001, around the time I became a consultant.

"While I am here, I feel deeply the losses in Syria. It's painful seeing what's happened there. But the people I work with in Sheffield are fantastic. The patients are wonderful and I'm happy where I am."

Teaching is important to Al-Mohammad. "I've learnt a lot over the 30 odd years since I became a doctor," he says, "Shortly, I will either retire or die and whatever I have learnt will go with me, so I need to share that knowledge by teaching. I feel a moral duty to teach."

Al-Mohammad was responsible for setting up a cardiac led heart failure outreach service across his Sheffield trust for which he won an NHS Hero award in 2012. Under the service, the cardiac team works collaboratively with a patient's physician and nurses in non-cardiac settings to identify patients with heart failure and provide specialist advice.

He has also won several grants for research projects and has contributed to national guidelines on several topics, most notably on heart failure for the National Institute for Health and Care Excellence.

Of Al-Mohammad's four children, two are now studying medicine. "They need to take it seriously and work hard. It's a very hard profession but extremely rewarding," he says. "What they do can make the difference between illness and health, and between life and death."

\section{Nominated by David Warriner}

Abdallah Al-Mohammad has inspired many medical students and junior doctors to become physicians and cardiologists in South Yorkshire.

$\mathrm{He}$ is an excellent bedside teacher, a gifted lecturer, and a dynamic leader in the NHS. He strives to turn any clinical interaction into a learning opportunity, regularly going above and beyond the call of duty for his trainees and, of course, his patients.

Despite being blessed with a razor sharp clinical acumen and a wealth of knowledge, not simply of heart failure and cardiology but across the whole landscape of medicine and beyond, he always remains humble and approachable.

As a mentor, his natural ability to make the complex simple, in the lab, clinic, or ward round, is what sets him apart as a role model.

David Warriner is a specialist registrar in cardiology.

Nominate a role model: To nominate someone who has been a role model during your medical career, send their name, job title, and the reason for your nomination to arimmer@bmj.com. 